\title{
INVESTIGATION INTO GRINDABILITY OF GH4169 SUPERALLOY AND EFFECTS OF GRINDING PARAMETERS ON THE SURFACE INTEGRITY
}

\author{
Quanren Zeng ${ }^{\mathrm{a}, \mathrm{b}}$, Geng Liu ${ }^{\mathrm{b}}$, Lan Liu ${ }^{\mathrm{b}}$ and Yi Qin ${ }^{\mathrm{a}, *}$ \\ ${ }^{a}$ Department of Design, Manufacture and Engineering Management, The University of \\ Strathclyde, Glasgow, G1 1XJ, UK
}

${ }^{\mathrm{b}}$ School of Mechanical Engineering, Northwestern Polytechnical University, Xi'an, 710072, Shaanxi, China 


\section{ABSTRACT}

GH4169, a nickel-base heat-resistant alloy, usually has outstanding high-temperature strength, excellent thermal stability and good wear resistance. However, it is hard to cut and its machined surface quality and integrity are particularly sensitive to a manufacturing process employed. The study reported in this paper was conducted to initially, review existing research on machining-induced surface integrity characteristics and machinability of some hard-to-cut materials, which was followed by a series of experiments focused on the effects of processing parameters on surface integrity of the GH4169 workpiece. Plain and external grinding tests were performed with various cutting parameters by using an $\mathrm{Al}_{2} \mathrm{O}_{3}$ wheel. For external grinding, an orthogonal test was designed to study the effect of the main grinding parameters on the surface integrity characteristics, which directly reflect the machinability of the material and its sensitivity to the specific grinding parameters. Machined surfaces were observed, and surface residual stress and microhardness were attained. Within a specified plain-grinding parameters range, additional measurements and observations beneath the ground surface were performed. The residual stress profile, the microhardness profile and the microstructure alteration below the machined surface were analyzed. It was shown that plain grinding with a low depth of cut (that is to say, low material removal rate) leads to potentially more acceptable surface quality with a lesser variation of residual stresses and microhardness values in the machining-affected zone than those obtained with high depth of cut. In addition, no severe microstructural alteration or adverse surface cracking will be discerned when the grinding parameter, depth of cut $a_{p}$, is reasonably set.

Keyword: grindability; surface integrity; surface roughness; residual stress; microhardness; microstructure 


\section{INTRODUCTION}

Superalloy, also known as heat-resistant alloy or high-temperature alloy, usually has outstanding high-temperature strength, excellent thermal stability, good corrosion and wear resistance. Superalloy can withstand complex stress and work reliably under an oxidation and gas corrosion environment even at $600^{\circ} \mathrm{C}-1100^{\circ} \mathrm{C}$. Consequently, it is widely employed for the hot sections in the aeroengines [1]. GH4169, a representative Ni-based superalloy, has been widely used as turbine discs, monoblock rotors, drive shafts, blisk and vane components in the aerospace industry because of it superior properties [2]. When machining GH4169 superalloy, its combination of properties like high-temperature strength, low thermal conductivity and strong work-hardening contributes to its undesirable and poor machinability. Further, its surface integrity characteristics and service performance are susceptible to the variation of the machining parameters and conditions, which leads to GH4169 superalloy being considered as typical difficult-to-machine material.

Surface integrity provides an effective means of characterizing and assessing the surface and subsurface features and related functionality [3]. Different cutting parameters and conditions usually will cause variations of the surface integrity characteristics and corresponding mechanical properties of the machined components, especially for some materials which are hard to cut. Poor surface integrity will deteriorate the surface state, form adverse stress concentration, initiate surface cracks, speed up the fatigue fracture and even constitute a potential danger for the machined components in service. For quite some time, many researches have focused on the machinability and surface integrity of difficult-to-machine materials for aerospace industry and other fields of applications [4]. 
Ezugwu summarized the machinability of difficult-to-machine materials such as aeroengine alloys, hardened steel and structural ceramics. These materials provide a serious challenge for cutting tool materials and usually result in concentration of high temperatures at the tool-workpiece interface during machining which strongly affect the surface quality of machined components [5]. Novovic compared the effects of surface topography and integrity on fatigue performance for conventional and non-conventional machined titanium alloy and steel [6]. Ulutan and Ozelove reviewed the machining induced surface integrity in titanium and nickel alloys for both aerospace and biometrical industry and they concluded that further modelling studies are needed to create predictive physical-based models that in good agreement with reliable experiment [7]. Considering that the surface integrity of a machined component will be mainly affected and could be controlled by its machining operational parameters when other machining conditions are settled down, many researches have been carried out to find their relationship for different manufacturing processes and materials. For instance, Jawahir analyzed and reviewed the works about surface texture effect on the surface integrity and related functional performance during material removal processes carried out in recent years [8]. Xu investigated the influence of machining-induced high temperatures on workpiece surface integrity in the surface grinding of a cast Ni-base superalloy K417 by using different machining parameters to achieving the change of temperature [9]. Zhao studied the variation of surface and subsurface integrity characteristics for diamond-ground optical glasses material by ultra-precision machining of fused silica and fused quartz assisted with electrolytic in-process dressing [10]. Bushlya researched how the turning parameters and conditions will influence the machinability of Inconel 718 components with coated and 
uncoated PCBN tools [11]. Ding investigated the effect of creep feed grinding process on the grindability and surface integrity of Ni-based alloy when using CBN wheels [12]. Further, researches have also been concerned with thermally induced machining damage, especially for the high speed machining or grinding of superalloy [13-15].

As compared with other difficult-to-machine superalloys or ceramic materials, GH4169 is comparatively new aerospace superalloy used for turbine blisk and shaft components. It has similar composition and mechanical properties with Inconel 718 (U.S. trademark) and $\mathrm{NC} 19 \mathrm{FeNb}$ (France trademark). Therefore, studies on the machinability of GH4169 superalloy, especially the related surface integrity characteristics like the 3D surface topography, residual stress and microhardness as well as the microstructure beneath the surface, are still relatively few. Kong researched the broaching performance and formation of saw-tooth chips during the high speed machining of GH1469 by using an FEM simulation technique [16]. Xue experimentally investigated the performance and the wear mechanisms of a PVD-TiAlN coated carbide tool in turning of GH4169 [17]. Grinding is normally used as the final finishing process for the critical components and it has been widely employed for the machining of superalloy used in the aerospace industry. When it comes to the machining-induced surface integrity aspects in the grinding of GH4169 superalloy, comprehensive studies focusing on both the grindability and related grinding-induced surface integrity characteristics effects are seldom found. During grinding with abrasive wheels, the excellent physical properties of GH4169 superalloy together with its poor thermal conductivity make it extremely difficult to be machined and usually lead to large grinding force and extra-high temperature at the grinding zone and consequently potential changes of 
the surface integrity characteristics within the machined surface layer. At present, it is still difficult to ensure the surface quality and integrity of the ground components of GH4169 superalloy than that of normal metal components during the mass production. In view of this, a systematic study of the grindability and the relationship between the machining parameters and the formation mechanism of the surface integrity characteristics for grinding of GH4169 superalloy is of practical engineering significance and urgency.

\section{MATERIAL AND EXPERIMENT}

\subsection{Material}

GH4169 superalloy composition is usually characterized by containing around $5 \% \mathrm{of} \mathrm{Nb}$, around $21 \%$ of $\mathrm{Cr}$, a small amount of $\mathrm{Al}$ and $\mathrm{Ti}$ to form its strengthening phases $\gamma^{\prime}\left(\mathrm{Ni}_{3}(\mathrm{AlTi})\right)$ and $\gamma^{\prime \prime}\left(\mathrm{Ni}_{3} \mathrm{Nb}\right)$ which can enhance the alloy's strength and ensure favorable combination properties within the operating temperature range of from $20^{\circ} \mathrm{C}$ to $750^{\circ} \mathrm{C}$. After direct aging treatment, the microstructure of GH4169 superalloy is usually comprised of its matrix material, $\gamma^{\prime}$ and $\gamma^{\prime \prime}$ strengthening phases dispersed in the matrix and fine particle $\delta$ phase mainly consolidating the grain boundaries (see Fig. 8). The nominal composition and physical properties of the workpiece material are given in Table 1 and Table 2, respectively [1-2].

Table 1. The nominal composition of GH4169 superalloy (wt. \%) [1]

\begin{tabular}{ccccccccc}
\hline $\mathrm{C}$ & $\mathrm{Cr}$ & $\mathrm{Ni}$ & $\mathrm{Co}$ & $\mathrm{Mo}$ & $\mathrm{Al}$ & $\mathrm{Ti}$ & $\mathrm{Nb}$ & $\mathrm{Fe}$ \\
\hline$\leq 0.08$ & $17-21$ & $50-55$ & $\leq 1$ & $2.8-3.3$ & $0.2-0.6$ & $0.65-1.25$ & $4.75-5.5$ & Balance \\
\hline $\mathrm{Mn}$ & $\mathrm{B}$ & $\mathrm{Mg}$ & $\mathrm{Si}$ & $\mathrm{P}$ & $\mathrm{S}$ & $\mathrm{Cu}$ & $\mathrm{Ca}$ & $\mathrm{Pb}$ \\
\hline$<0.35$ & $<0.006$ & $<0.01$ & $<0.35$ & $<0.015$ & $<0.015$ & $<0.30$ & $<0.01$ & 0.0005 \\
\hline
\end{tabular}


Table 2. The physical and mechanical properties of GH4169 [1-2]

\begin{tabular}{|c|c|c|c|c|c|c|c|c|}
\hline $\begin{array}{c}\mathrm{T} \\
\left({ }^{\circ} \mathrm{C}\right)\end{array}$ & $\begin{array}{c}\text { Yield } \\
\text { strength } \\
\sigma_{0.2} \\
(\mathrm{MPa})\end{array}$ & $\begin{array}{c}\text { Tensile } \\
\text { strength } \\
\sigma_{\mathrm{b}} \\
(\mathrm{MPa})\end{array}$ & $\begin{array}{l}\text { Elongation } \\
\qquad \delta_{5}(\%)\end{array}$ & $\begin{array}{c}\text { thermal } \\
\text { conductivity } \\
\left(\mathrm{W} / \mathrm{m},{ }^{\circ} \mathrm{C}\right)\end{array}$ & $\begin{array}{c}\text { modulus of } \\
\text { elasticity E } \\
(\mathrm{GPa})\end{array}$ & $\begin{array}{l}\text { melting } \\
\text { point } \\
\left({ }^{\circ} \mathrm{C}\right)\end{array}$ & $\begin{array}{c}\text { Hardness } \\
(\mathrm{HV})\end{array}$ & $\begin{array}{l}\text { Density } \\
\left(\mathrm{g} / \mathrm{cm}^{3}\right)\end{array}$ \\
\hline 20 & 1240 & 1450 & $>10$ & 13.4 & 205 & 1310 & $376-480$ & 8.24 \\
\hline 650 & 1000 & 1170 & $>12$ & 22.1 & 205 & - & - & - \\
\hline 750 & 740 & 950 & 25 & 23.5 & - & - & - & - \\
\hline
\end{tabular}

The actual measured value of the microhardness of the workpiece material for the grinding experiment is around $480 \mathrm{HV}$. This workpiece for grinding experiments is supplied in two forms. One is a bar of size $\varphi 30 \times 100 \mathrm{~mm}(30 \mathrm{~mm}$ diameter and $100 \mathrm{~mm}$ length) for orthogonal design experiment of external grinding, whilst the second is a rectangular block of size $30 \times 25 \times 10 \mathrm{~mm}$ for single-factorial experiment of plain grinding.

\subsection{Equipment}

A single alundum grinding wheel with $\mathrm{Al}_{2} \mathrm{O}_{3}$ abrasive grit was employed for grinding experiments, having an abrasive grit size of 80\#. The cutting fluid used was a normal 5\% emulsion. The 3D surface texture and roughness were measured by using a Veeco NT 1100 3D white light interferometer with a resolution of $2 \mathrm{~nm}$ on the optical Z-axis. The measurement of surface residual stress and the residual stress profile (variations of residual stress with the depth below surface) were made using the XA-350 x-ray stress analysis system. The measurement of surface microhardness and microhardness profile (variations of microhardness with the depth below surface) were conducted by using Everone MH-50 microhardness tester with a load of $25 \mathrm{~g}$ and a hold time for $10 \mathrm{~s}$. Subsurface microstructures were also revealed and analyzed with the metallographic microscope technique. 


\subsection{Procedures}

\subsubsection{Grinding arrangement}

Orthogonal experimental design is a scientific method that can investigate multiple factors effects on the researched objective function [18]. The orthogonal table can reduce the total number of trials and increase the amount of information of the tested points. Compared to the trial number of factorial design experiments, only a few representative tests are needed to determine the most significant factor that may affect the researched objective function. For external grinding of the GH4169 superalloy, the processing parameters are the main factors affecting the surface integrity characteristics once the wheel properties and lubrication conditions are established. A three-factors four-levels orthogonal experiment $\left(\mathrm{L}_{16}\left(4^{5}\right)\right)$ for external grinding was designed, as shown in Table 3. The three factors investigated here are

Table 3. Orthogonal design external grinding tests \& SI characteristics measurement

\begin{tabular}{ccccccc}
\hline \multirow{2}{*}{$\begin{array}{c}\text { Samples } \\
\text { No. }\end{array}$} & \multicolumn{2}{c}{ Grinding parameters } & \multicolumn{2}{c}{ SI characteristics measurement } \\
\cline { 2 - 7 } & $v_{\mathrm{w}}$ & $a_{\mathrm{p}}$ & $v_{\mathrm{s}}$ & $R_{a}$ & $\sigma_{R 0}$ & $H V_{l}$ \\
& $(\mathrm{~m} / \mathrm{min})$ & $(\mathrm{mm})$ & $(\mathrm{m} / \mathrm{s})$ & $(\mu \mathrm{m})$ & $(\mathrm{MPa})$ & $\left(\mathrm{kgf} / \mathrm{mm}^{2}\right)$ \\
\hline EG1 & 8 & 0.005 & 15 & 0.259 & -241.8 & 512.38 \\
EG2 & 8 & 0.01 & 20 & 0.298 & -383.1 & 539.71 \\
EG3 & 8 & 0.015 & 25 & 0.260 & -161.1 & 501.33 \\
EG4 & 8 & 0.02 & 30 & 0.299 & -467.3 & 508.59 \\
EG5 & 12 & 0.005 & 20 & 0.210 & -438.9 & 539.91 \\
EG6 & 12 & 0.01 & 15 & 0.268 & -210.1 & 478.76 \\
EG7 & 12 & 0.015 & 30 & 0.289 & -83.4 & 473.76 \\
EG8 & 12 & 0.02 & 25 & 0.2423 & -554.6 & 494.21 \\
EG9 & 16 & 0.005 & 25 & 0.268 & -354.2 & 531.77 \\
EG10 & 16 & 0.01 & 30 & 0.232 & -460.2 & 494.21 \\
EG11 & 16 & 0.015 & 15 & 0.293 & -550.3 & 487.25 \\
EG12 & 16 & 0.02 & 20 & 0.296 & -334.2 & 504.85 \\
EG13 & 22 & 0.005 & 30 & 0.247 & -493.2 & 487.08 \\
EG14 & 22 & 0.01 & 25 & 0.285 & -453.3 & 508.78 \\
EG15 & 22 & 0.015 & 20 & 0.257 & -190.4 & 508.59 \\
EG16 & 22 & 0.02 & 15 & 0.324 & -215.3 & 556.13 \\
\hline
\end{tabular}

wheel speed $v_{s}$, workpiece speed $v_{w}$ and depth of cut $a_{p}$. They are taken as independent 
variables for the orthogonal design. The levels for each factor are: wheel speed $v_{s}=15,20,25$, $30 \mathrm{~m} / \mathrm{s}$; workpiece speed $v_{w}=8,12,16,22 \mathrm{~m} / \mathrm{min}$; depth of cut $a_{p}=0.005,0.01,0.015,0.02 \mathrm{~mm}$. The workpiece sample size $\varphi 30 \times 100 \mathrm{~mm}$. The linear regression analysis method is then employed to help to establish the empirical correlation between the grinding parameters and surface roughness characteristic. Accurately establishing and analyzing the empirical relationships can help to find the most influencing factors and guide the selection of a reasonable range of operational parameters for the actual grinding process and will certainly decrease the trial-producing time and machining cost as well as attaining acceptable surface quality when grinding GH4169 superalloy.

Further, single-factorial plain grinding tests were designed and listed in Table 4 , in which the effect of depth of cut $a_{p}$ on the surface integrity characteristics such as surface roughness, residual stress and microhardness distribution and microstructure beneath the machined surface are quantitatively compared and analyzed in detail. The wheel speed and workpiece speed are specified as $v_{s}=25 \mathrm{~m} / \mathrm{s}$ and $v_{w}=10 \mathrm{~m} / \mathrm{min}$ respectively; while the depth of cut $a_{p}$ monotonically increases from $0.005 \mathrm{~mm}$ to $0.04 \mathrm{~mm}$. A reasonable value of depth of cut will give good surface quality and integrity characteristics on the ground surface.

Table 4. Single-factorial test of GH4169 plain grinding \& SI characteristics measurement

\begin{tabular}{|c|c|c|c|c|c|c|}
\hline $\begin{array}{c}\text { Sample } \\
\text { No. }\end{array}$ & $\begin{array}{c}v_{\mathrm{w}} \\
(\mathrm{m} / \mathrm{min})\end{array}$ & $\begin{array}{c}v_{\mathrm{s}} \\
(\mathbf{m} / \mathbf{s})\end{array}$ & $\begin{array}{c}a_{\mathbf{p}} \\
(\mathbf{m m})\end{array}$ & $\begin{array}{c}\text { Residual stress } \\
\text { vs. depth below } \\
\text { surface } \\
\end{array}$ & $\begin{array}{c}\text { Microhardness } \\
\text { vs. depth } \\
\text { below surface } \\
\end{array}$ & $\begin{array}{c}\text { Microstructure } \\
\text { vs. depth } \\
\text { below surface }\end{array}$ \\
\hline PG1 & \multirow{5}{*}{10} & \multirow{5}{*}{25} & 0.005 & $\sigma_{R}=\sigma_{R}(h) *$ & $H V=H V(h) * *$ & $* * *$ \\
\hline PG2 & & & 0.015 & $\sigma_{R}=\sigma_{R}(h) *$ & $\bar{\square}$ & 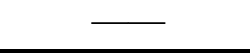 \\
\hline PG3 & & & 0.025 & $\sigma_{R}=\sigma_{R}(h) *$ & $H V=H V(h) * *$ & $* * *$ \\
\hline PG4 & & & 0.035 & $\sigma_{R}=\sigma_{R}(h) *$ & 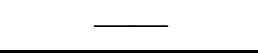 & - \\
\hline PG5 & & & 0.04 & $\sigma_{R}=\sigma_{R}(h) *$ & $H V=H V(h) * *$ & $* * *$ \\
\hline
\end{tabular}

*: refer to Fig. 3\&4; $\quad$ **: refer to Fig.7; $\quad * * *$ : refer to Fig.9; 


\subsubsection{Measurement and characterisation}

This research combines different techniques to measure and characterize the cutting performance and surface integrity characteristics of the ground surface. The surface topography and roughness of the machined surface were observed and analyzed with the 3D white light interferometric microscopy technique and scanning electron microscopy. The surface roughness was measured at 3 different positions on a machined sample using an optical interferometer and taking the average as the final surface roughness value $R_{a}$.

The X-ray stress analysis technique and local layer-peeling method were used to measure surface residual stress and subsurface residual stress distribution for external and plain ground samples. The surface and subsurface residual stresses were attained using X-350A x-ray stress analysis system with a $\mathrm{Cr}$-anticathode, piping current $\mathrm{I}=8 \mathrm{~mA}$, piping voltage $\mathrm{U}=25 \mathrm{kV}$. The subsurface residual stresses were measured layer by layer with the help of an electrolytic corrosion device for local layer peeling.

The microhardness of the machined surface was measured using a microhardness tester with the beveling plane method. With this method, a small plane with around $3^{\circ}$ inclination to the ground surface was beveled and polished. Microhardness measurements were carried out at the different location of the bevel plane which actually gave the microhardness with different depths below the ground surface. The polished bevel plane also makes the boundary of the diamond indentation more clearly discerned and will help to accurately calculate the value of microhardness (See Fig.6).

The subsurface microstructure and grain morphology of the workpiece material were observed using scanning electron microscope. Detailed metallurgical variation of the microstructure of the samples that were ground with three different depth of cut $a_{p}$ were 
compared with the results obtained using the metallographic microscope technique.

\section{RESULTS AND DISCUSSION}

\subsection{Surface roughness and effects}

\subsubsection{Orthogonal design experiment for external grinding}

The 3D surface topography for some of the machined samples are visually presented in Fig. 1.

With the specified external grinding parameter range, the ground surfaces are of comparatively lower roughness value and the maximum surface roughness is $R_{a}=0.324 \mu \mathrm{m}$; there are prominent grinding marks and lays along the machining direction on the workpiece surface.

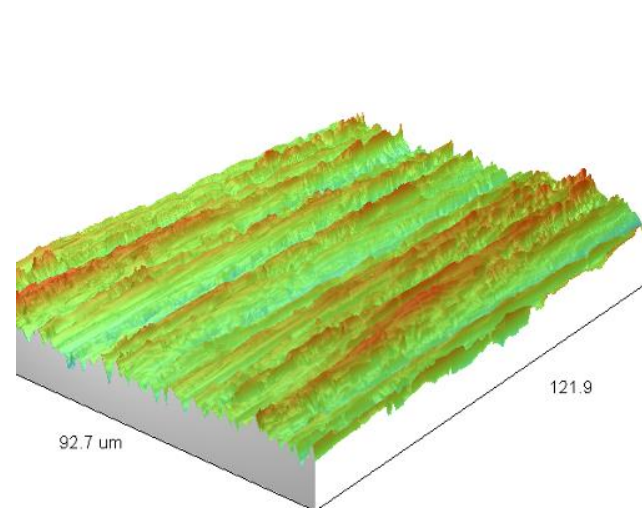

(a) EG1: $R_{a}=0.259 \mu \mathrm{m}$

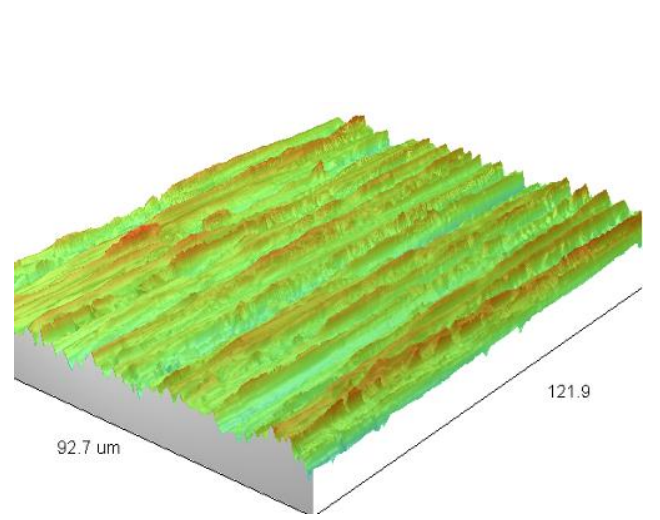

(c) EG5: $R_{a}=0.210 \mu \mathrm{m}$
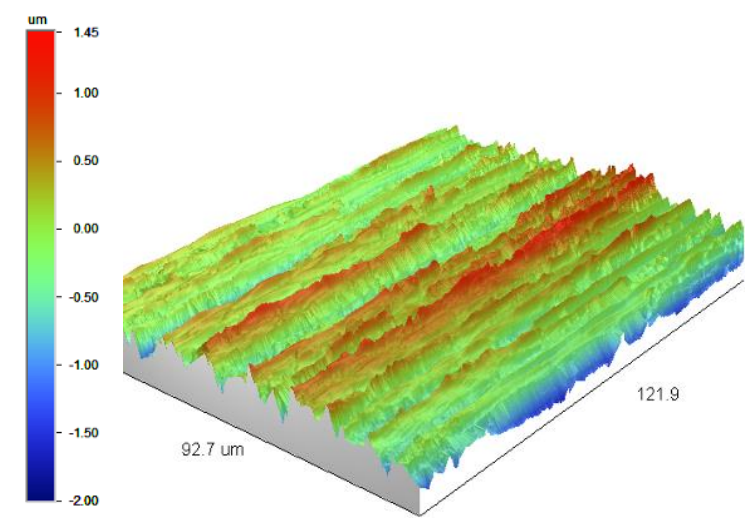

(b) EG2: $R_{a}=0.298 \mu \mathrm{m}$
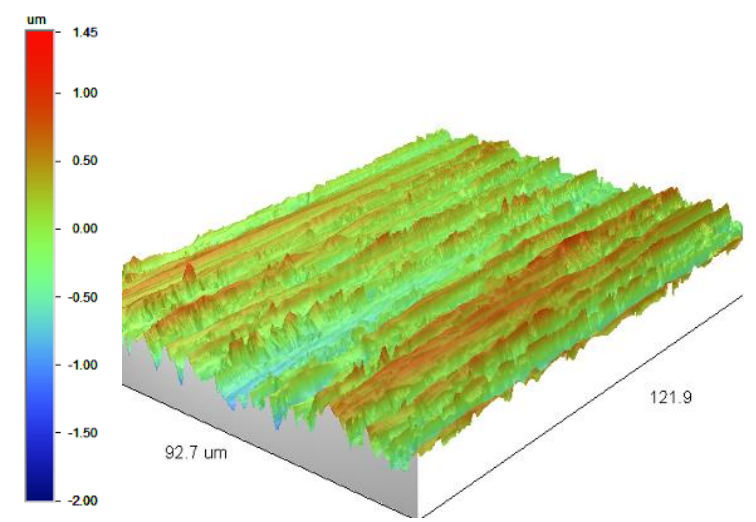

(c) EG6: $R_{a}=0.268 \mu \mathrm{m}$

Fig. 1 3D surface texture of external ground components for orthogonal experiments

Seen in Fig.1, samples EG2 and EG6 were ground with a comparatively higher value of depth 
of cut, and their ground 3D surfaces obviously contain deeper grooves and higher peaks when compared with those of samples EG1 and EG5. Correspondingly, the surface roughness values of samples EG2 and EG6 are larger than those of samples EG1 and EG5 respectively.

According to the arrangement of grinding parameters and the measured values of surface integrity characteristics in Table 3, an empirical equation which expressing the correlation between the measured surface roughness $R_{a}$ and the 3 main grinding parameters within the range researched is derived from linear regression analysis as follows:

$$
R_{a}=10^{-0.228} \cdot v_{w}^{0.01} \cdot a_{p}^{0.112} \cdot v_{s}^{-0.101}
$$

Although the correlative coefficient and the significance level are not desirable, this empirical equation still offers some helpful information. Within the grinding parameter range researched, the depth of cut $a_{p}$ is of the maximum power-law index among 3 main grinding parameters and is the most important factor that affects the surface roughness $R_{a}$. From the empirical equation, the depth of cut $a_{p}$ is positively correlated to the surface roughness, which means $R_{a}$ will decrease with the decrease of $a_{p}$; the workpiece speed $v_{w}$ is comparatively less correlative to the surface roughness $R_{a}$; while the wheel speed $v_{s}$ is negatively correlated to the surface roughness, which means $R_{a}$ will reduce if wheel speed $v_{s}$ increases. Within the grinding parameter range researched, the surface quality and roughness could correspondingly be improved by reasonably increasing the wheel speed $v_{s}$, or by reducing the depth of cut $a_{p}$.

\subsubsection{Single-factorial experiment for plain grinding}

A single-factorial grinding test, which focuses on investigation of the effect of depth of cut $a_{p}$ on the surface integrity characteristics such as surface roughness, residual stress and microhardness distribution and microstructure beneath the surface, was designed, as shown in 
Table 4. The 3D surface topography of these plain-ground samples are visually displayed in Fig. 2. As can be seen, the effect of depth of cut $a_{p}$ on surface roughness and topography is very apparent and intensive. When the wheel speed and workpiece speed are specified, surface roughness will monotonically soar with increase of the depth of cut $a_{p}$. For the sample PG1 ground with $a_{p}=0.005 \mathrm{~mm}$, the surface roughness is low and $R_{a}=0.284 \mu \mathrm{m}$. For the sample PG3 ground with $a_{p}=0.015 \mathrm{~mm}$, the surface has obvious grooves and peaks with $R_{a}=0.421 \mu \mathrm{m}$. For the sample PG5 ground with $a_{p}=0.04 \mathrm{~mm}$, the grooves are much deeper and the peaks disperse more widely on the ground surface with a roughness value of $R_{a}=0.896 \mu \mathrm{m}$ which is much larger than those of sample PG1 and PG3.

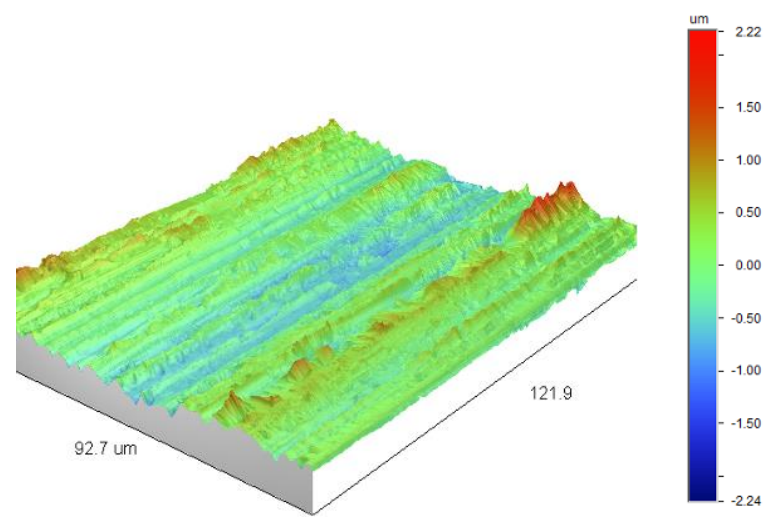

(a) PG1: $R_{a}=0.284 \mu \mathrm{m}$,

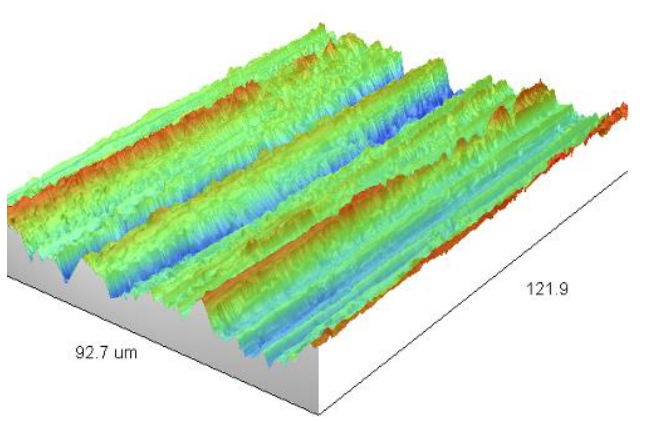

(b) PG3: $R_{a}=0.421 \mu \mathrm{m}$

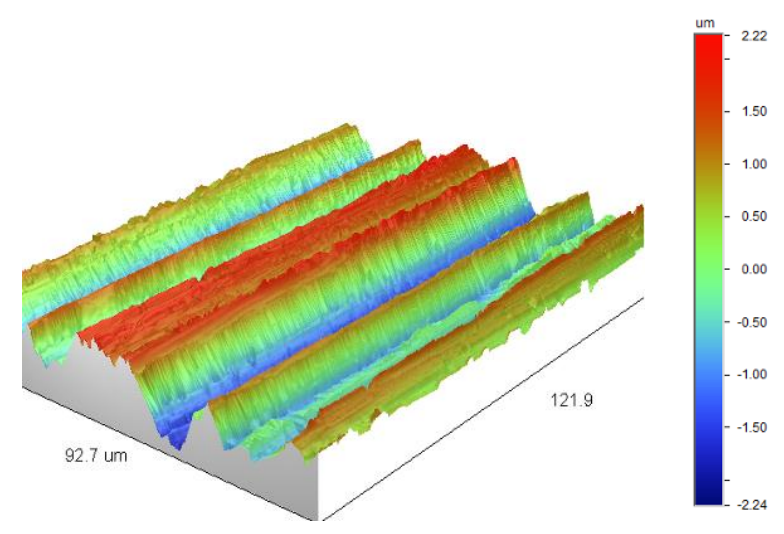

(a) PG5: $R_{a}=0.896 \mu \mathrm{m}$

Fig. 2 3D surface texture of plain ground components for single-factorial experiments 


\subsection{Surface and subsurface residual stress and effects}

Generally, the formation mechanism and influencing factors of residual stress for ground surfaces mainly originate from two aspects [19-20]. One is from the machining-induced thermal effect and it usually has much more in-depth influence on a material of low thermal conductivity with worse machining condition; another is from the machining-induced mechanical action or plastic deformation. During the cutting process, massive cutting heat will be produced on the interface between the tool and the workpiece. The heat energy is then transferred to the subsurface layer and even to the core of the workpiece; therefore the local high temperature will make the volume of the surface and subsurface material swell and firstly produce a kind of compressive stress. Considering the low thermal conductivity of GH4169 material, the grinding heat will mainly accumulate in a thin layer near the surface while the core and bulk material of the workpiece will keep at a comparatively low temperature or even ambient temperature during the limited machining process. After the cutting tool has left the workpiece surface, the heated and swelled subsurface layer is then gradually cooled and tends to contract, but the bulk material will prevent the surface and subsurface layer from contracting or shrinking at that time, so residual tension is likely to be present on the newly machined surface and subsurface layer. Consequently, the thermal effect is finally prone to produce tensile residual stress on the machined surface of the workpiece. In the meantime, the mechanically-induced (or deformation-led) residual stress during the grinding process can be explained by a combination of plastic deformation in the superficial surface layer and elastic deformation in the underlying surface. When the mechanical-cutting action stops, the elastic deformation below the subsurface layer tends to restore while the 
plastically-deformed thin superficial layer is inclined to counteract its springing back. To achieve force equilibrium and geometric compatibility after the grinding process, elastic rebalancing and existing plastic deformation will place the surface and superficial layer in the state of residual compressive stress.

GH4169 superalloy has excellent mechanical properties and usually exhibits severe work-hardening. It also combines the poor thermal conductivity with tough and strengthened phases in its matrix material. Generally, its machinability is not as good as its mechanical properties. During grinding, grinding heat is built up easily in the cutting zone, which deteriorates the cutting condition and degrades the tool life. As a result, high cutting forces with high localized temperatures are produced around the grinding wheel surface and the workpiece surface, thus leading to high values of surface roughness and tensile residual stress.

\subsubsection{Analysis of residual stress distribution below surface}

The residual stress distribution of the samples that have been plain-ground with different machining parameters are measured and compared. As shown in Fig. 3, the residual stresses distribution over the depth below surface $h$ of the workpiece, are presented in terms of two directions: $\sigma_{R x}$, parallel to the grinding direction and $\sigma_{R y}$, perpendicular to the grinding direction. 


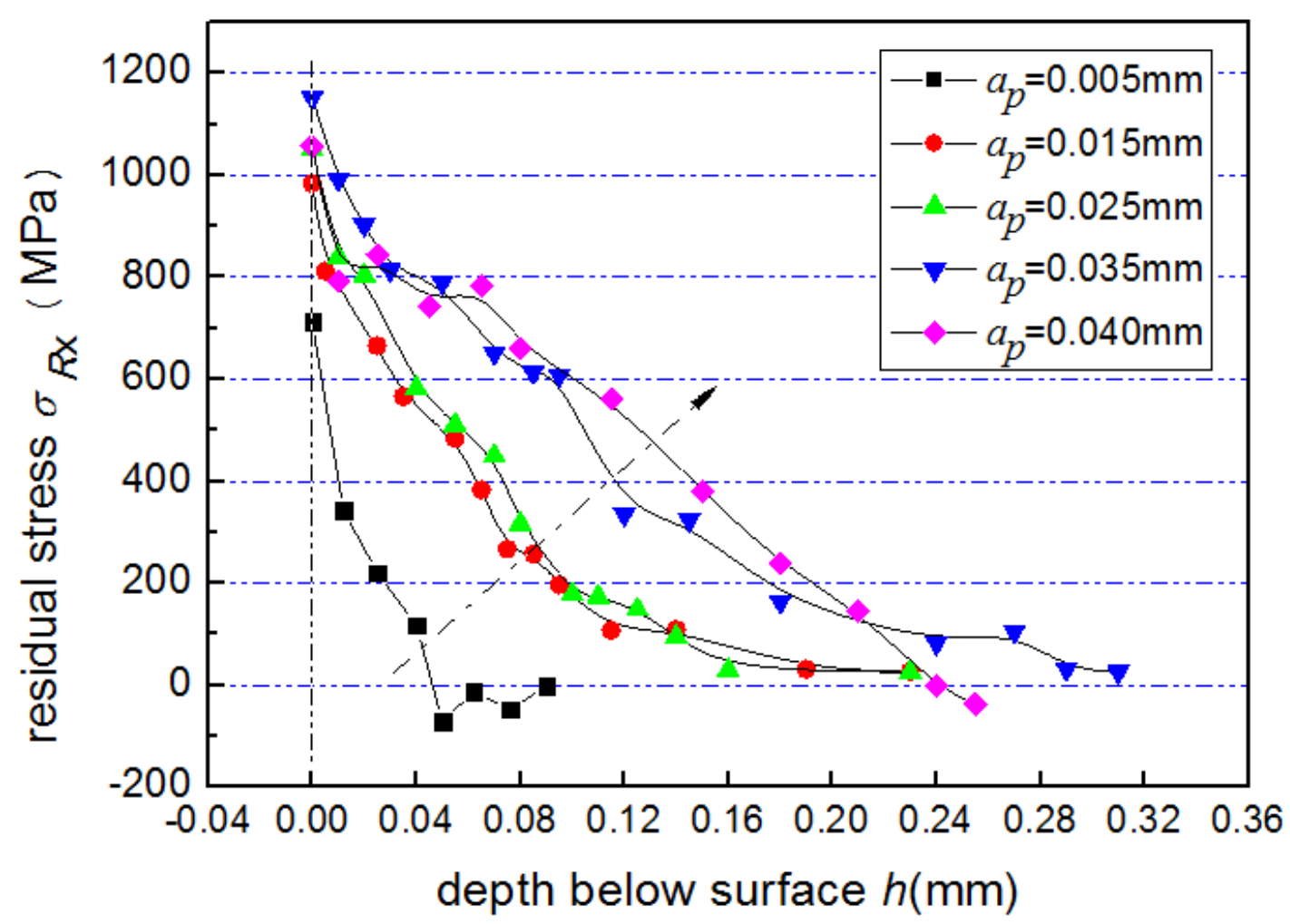

Fig. $3 \sigma_{R \mathrm{x}}$ distributions over the depth below surface for different plain-ground samples

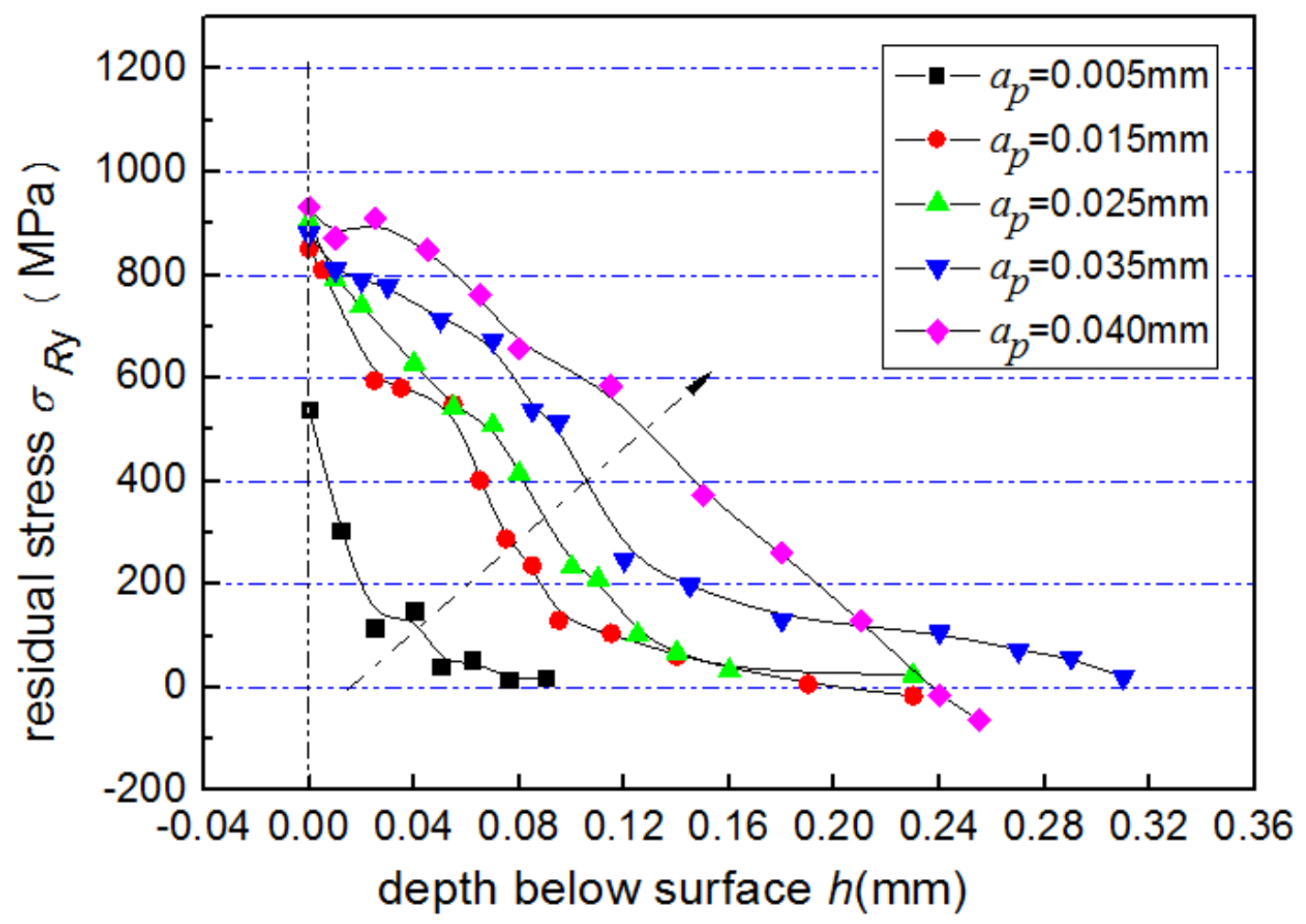

Fig. $4 \sigma_{R y}$ distributions over the depth below surface for different plain-ground samples 
From the residual stress distribution profiles shown in Fig. 3 and Fig.4, some findings and analyses are listed as follow: (1) the plain ground surfaces are mainly of adverse tensile residual stresses when compared to external grinding. This is caused by the low thermal conductivity of GH4169 superalloy and the adverse cutting condition around the interface of the workpiece and the grinding wheel. The thermally diffusive condition of plain grinding is usually worse than that of the external grinding, and massive grinding heat is accumulated at the outermost of the ground surface producing higher grinding temperature at this location. At this moment, the thermal effect is more significant and the ground surface will take on tensile residual stress according to the thermal-mechanical coupling action. (2) the magnitude of the tensile residual stress closely depends on the grinding parameters like depth of cut $a_{p}$ for this single-factorial plain grinding test. The residual stress $\sigma_{R x}$, which is parallel to the grinding direction and $\sigma_{R y}$, which is perpendicular to the grinding direction, are generally of the same order of magnitude, although $\sigma_{R \mathrm{x}}$ at the surface is around 250Mpa larger that $\sigma_{R \mathrm{y}}$ at the sample surface when $a_{p}=0.035 \mathrm{~mm}$. With the value of the depth below surface, $h$, increases, the tensile $\sigma_{R \mathrm{x}}$ and $\sigma_{R \mathrm{y}}$ both will monotonically decrease no matter what the value of $a_{p}$ is. For the residual stress $\sigma_{R x}$, it decreases rapidly when the depth below surface, $h$, is smaller than $40 \mu \mathrm{m}$. The residual stress decreases more gradually when the depth below surface, $h$, is larger than $200 \mu \mathrm{m}$. When the value of depth of cut $a_{p}$ increases, the tensile $\sigma_{R \mathrm{x}}$ and $\sigma_{R \mathrm{y}}$ both will rise; and the thickness of the subsurface zone where residual stress prevails will also obviously increase with the increase of depth of cut $a_{p}$. Usually, the increase of depth of cut $a_{p}$ will intensify the plastic deformation, improve the grinding energy input and lead to a fast rise of the grinding temperature at the machined interface. Finally, high tensile residual stress on the 
plain-ground surface and subsurface will develop due to the more significant thermal effect. When the of depth of cut $a_{p}$ increases from $0.005 \mathrm{~mm}$ to $0.04 \mathrm{~mm}$, the thickness of subsurface zone where residual stress effects are present will increase from around $100 \mu \mathrm{m}$ to $310 \mu \mathrm{m}$.

\subsection{Surface and subsurface microhardness and effects}

During machining process like grinding, the workpiece surface will usually experience severe plastic deformation and its grain structure and lattices in the vicinity of machined surfaces will be distorted or elongated and appear to be a kind of high-level fibrous structure. This kind of mechanical action usually will make the surface microhardness much higher than that of the bulk material. At the same time, most of the plastic deformation energy is converted into heat energy during the grinding of a GH4169 workpiece. Although the ground chips will take away quite a substantial part of the heat energy, there is still a large portion of grinding heat that will build up at the thin superficial layer of the workpiece which could not be quickly passed into the core and bulk material in time due to the intensive frictional interaction at the interface and low thermal conductivity of GH4169 superalloy. Thus, the surface and subsurface layer of the workpiece will be experiencing the equivalent to a high-temperature surface tempering or recrystallization process along with the work-hardening mechanical action. As is known, tempering is a process of heat treatment and will usually increase the toughness of alloys and reduce some of the excess hardness. That is to say, the surface tempering process essentially will eliminate the unbalanced microstructure and physical properties of the machined surface with grain growth or recrystallization, which finally softens the surface and subsurface material. Generally speaking, the workpiece 
material will mostly maintain its work-hardening effect when the temperature is below 0.4-0.5 times of the material's melting point. However, if the temperature further increases, both the material flow stress and material strength will decrease. Thereby, the extent of work hardening caused by the plastic deformation will be weakened when the surface tempering occurs at high temperature during grinding [22].

Considering the interaction of the work-hardening effect and the possible surface tempering caused by local high-temperature during the grinding of GH4169, there are likely 3 kinds of scenarios of the variation of microhardness within the subsurface layer:

(1) if the abrasive grits of the grinding wheel are sharp and the lubrication condition is good, and if the grinding material removal rate is well controlled, then the machined surface will not experience surface tempering or grinding burn and will mainly be work-hardened: its microhardness profile will usually have a peak value at the machined surface as Fig. 5(a) shown.

(2) if the abrasive grits are dull and if the grinding material removal rate is unreasonably high, massive grinding heat will gather around the machined surface and produce local high temperature at the outermost thin superficial layer of the machined surface. Once this temperature is above tempering temperature or the transformation temperature of the superalloy, the microstructure near this area will gradually change to equiaxed grains, the strengthening phase in the alloy may be resolved and the microhardness of this area will drop rapidly. However, its underlying layer near the core will keep the effect of cold deformation strengthening due to the large grinding force and inaccessibility of grinding heat. With the depth below surface $h$ increases, the microhardness value at the surface and subsurface will 
firstly go below that of the bulk material $H V_{0}$, then increase to a peak and finally approach the hardness of the bulk material, as shown in Fig.5(b)

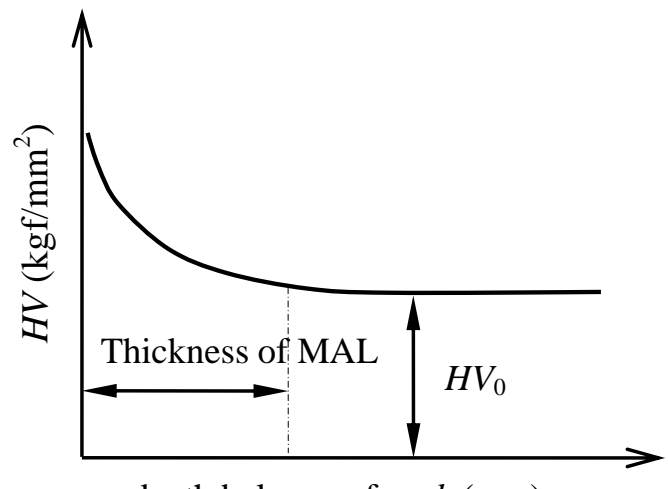

depth below surface $h(\mathrm{~mm})$

(a)

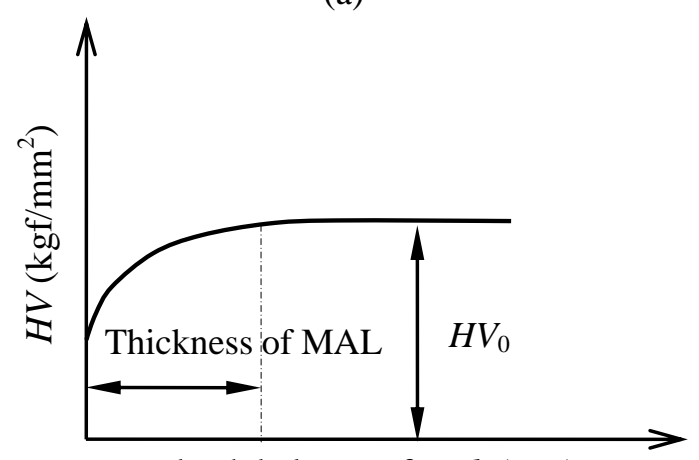

depth below surface $h(\mathrm{~mm})$

(c)

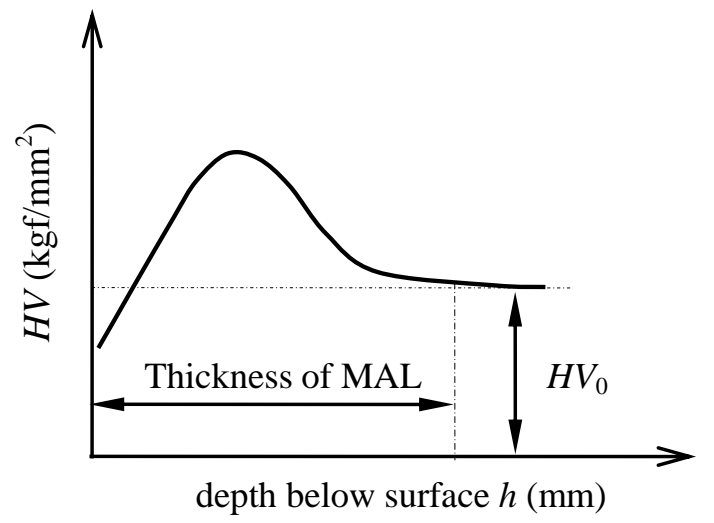

(b)

Fig.5 The mechanism for formation of microhardness of ground surface

(3) if the lubrication is insufficient or with dry grinding, the grinding state around the interface will rapidly deteriorate and the grinding temperature will exceed the recrystallization or tempering temperature. Then the whole surface and material-altered-layer (MAL) will experience severer thermal action and sometimes even grinding burn may occur. As a result, the microhardness of the surface and subsurface will all be below that of the bulk material $H V_{0}$, as shown in Fig.5(c). 


\subsubsection{Effect of grinding parameters on microhardness}

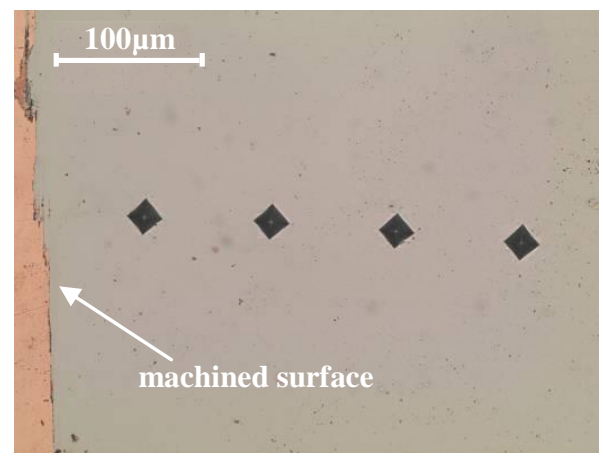

(a) $200 \mathrm{X}$

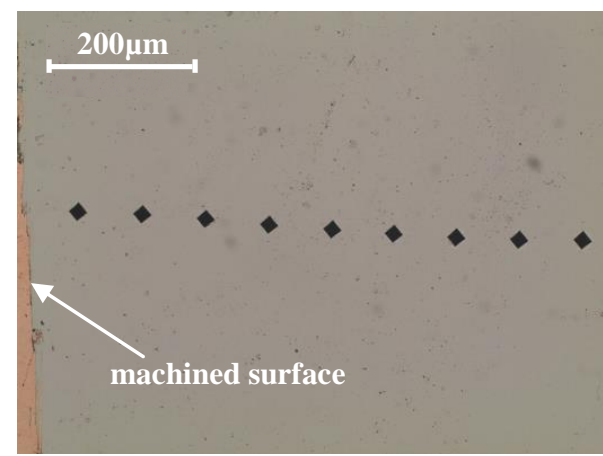

(b) $100 \mathrm{X}$

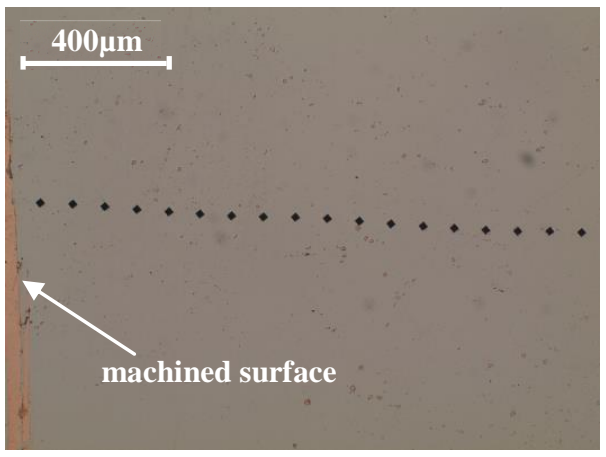

(c) $50 \mathrm{X}$

Fig. 6 Microhardness measurement process

Fig.6 shows the measurement process of microhardness and the indentation marks on a polished bevel plane. The actual variation of microhardness values with the depth below surface from the single-factorial test are shown in Fig. 7. The surface microhardness values of the samples PG1, PG3 and PG5 are respectively $H V_{1}=440,435$ and 417 . They are obviously lower than the value of the bulk material $\left(H V_{0} \approx 480\right)$. The effect of work-hardening does not show up in this case; the surface and subsurface are actually softened. It is mainly because the thermal conductivity of GH4169 is comparatively low and a mass of thermal energy could not be quickly passed into the core, but congregating only at the superficial layer of the ground surface. This will cause extremely high temperature at the ground surface layer and once the temperature exceeds the tempering temperature or is higher than the solution temperature of the strengthening phase $\gamma^{\prime}$ or $\gamma^{\prime \prime}$, the material microstructure of the surface layer will change, the grains structure will grow and the strengthening phases may be dissolved. Then the mircohardness of the surface and whole material-altered layer will fall to a low value. 


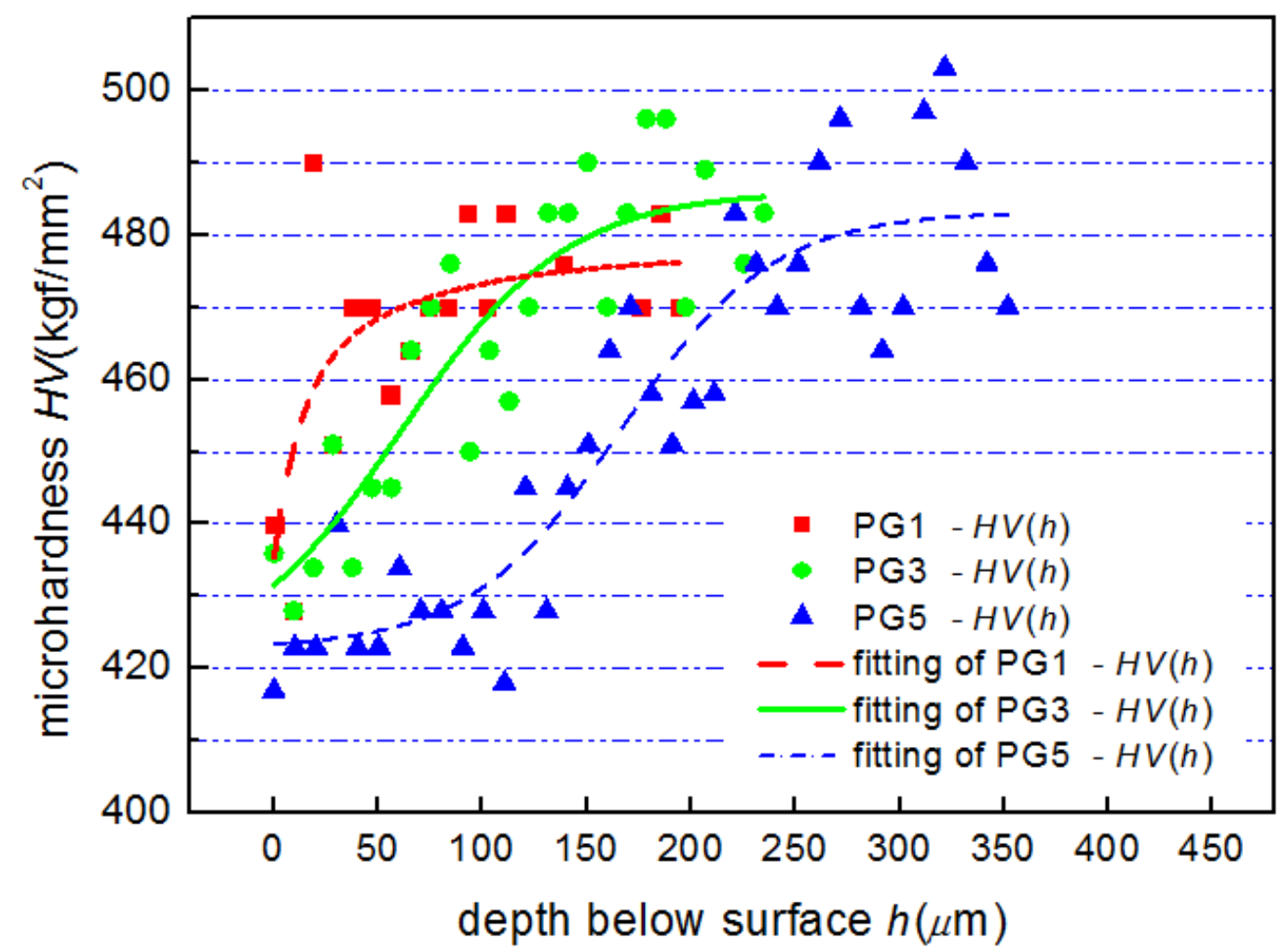

Fig.7 Microhardness profile varies with depth below surface for plain grinding test

As the depth of cut $a_{p}$ increases (from sample PG1 to PG5), the related plastic deformation will increase and more mechanical energy will transfer to thermal energy. Therefore, the temperature at the interface of the workpiece and grinding wheel periphery will soar to a value which exceeds the tempering temperature of the GH4169 material and make the measured values of microhardness have a prompt drop. As shown in Fig. 7, the outermost surface microhardness of sample PG1(with $a_{p}=0.005 \mathrm{~mm}$ ) does not drop too much and is around $H V_{1}=440$; while for the sample PG5(with $a_{p}=0.04 \mathrm{~mm}$ ), its surface and subsurface endure much more thermal effects due to the large grinding parameter and the value of microhardness drops to the lowest of around $H V_{1}=417$. With the increase of the depth below surface $h$, the microhardness value will gradually approach to that of the bulk material. The thickness of the material-altered layer where the microhardness varies will increase with the increase of depth of cut $a_{p}$. When $a_{p}$ increases from $0.005 \mathrm{~mm}$ to $0.04 \mathrm{~mm}$, the thickness of the 
region of microhardness variation will go up from $200 \mu \mathrm{m}$ to $360 \mu \mathrm{m}$.

\subsection{Subsurface microstructure and effects}

GH4169 superalloy usually needs to experience aging treatment to attain saturated $\mathrm{Ni}$ austenite and secure better mechanical properties. The microstructure of the GH4169 superalloy is shown in Fig.8(a). The grains are distributed homogenously within the field of view. The grain size is well-proportioned and the grain boundary is clear to discern. When the magnification increases to $2000 \mathrm{X}$, the inhomogeneous structure $\delta$ phase will be clearly observed. The $\delta$ phase structures are granular or like a short bar and are mainly dispersed in the grain boundary (or within grains) which will help to strengthen the material matrix.

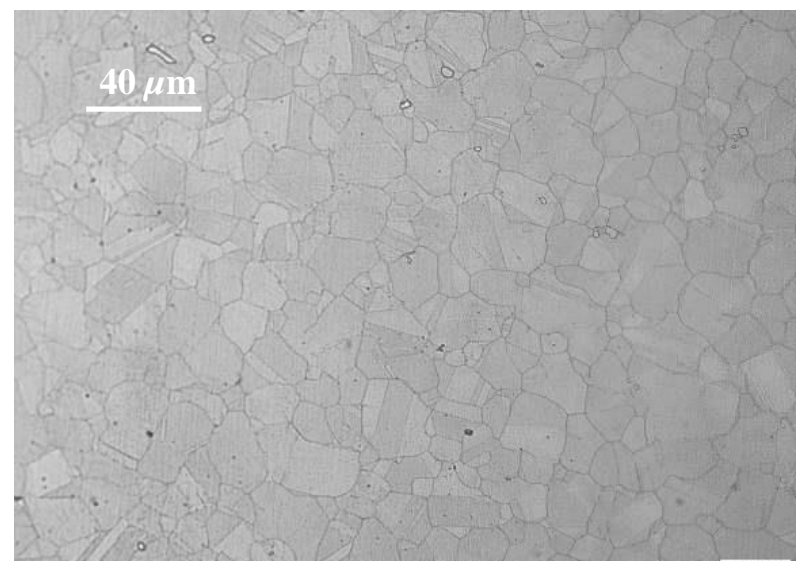

(a) Grain size and morphology of GH4169 superalloy (500X)

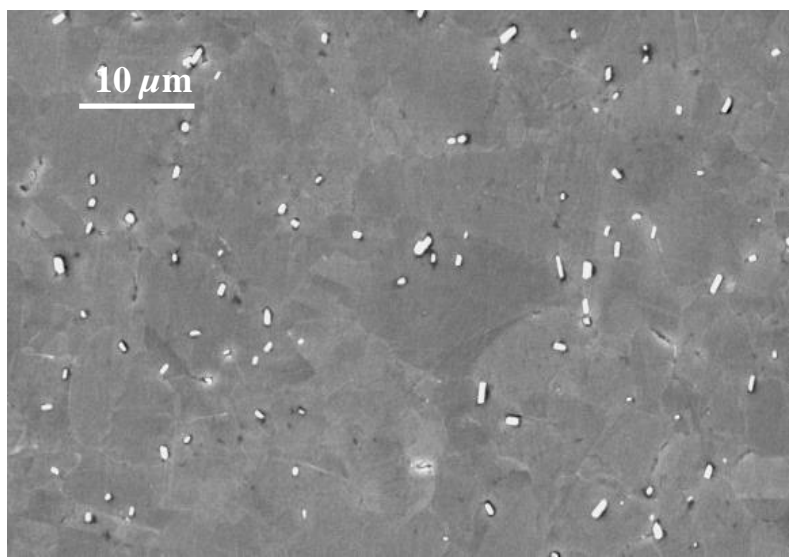

(b) Grain morphology with granular $\delta$ phase of GH4169 superalloy (2000X)

Fig.8 Microstructure of GH4169 superalloy 


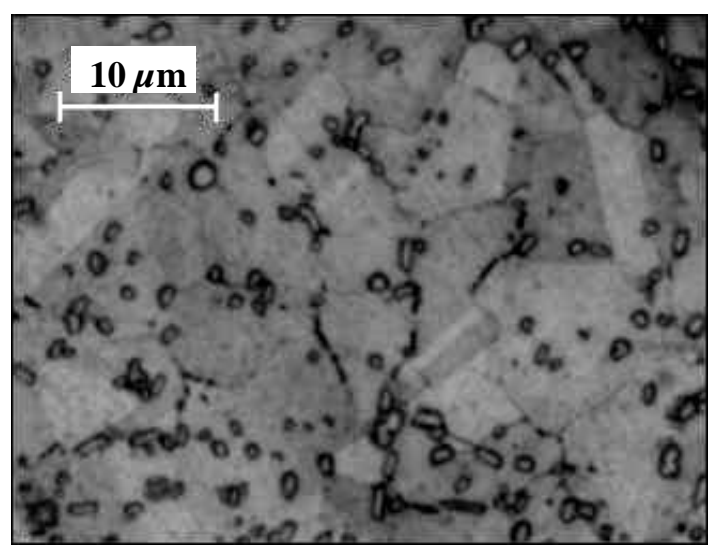

(a) bulk material

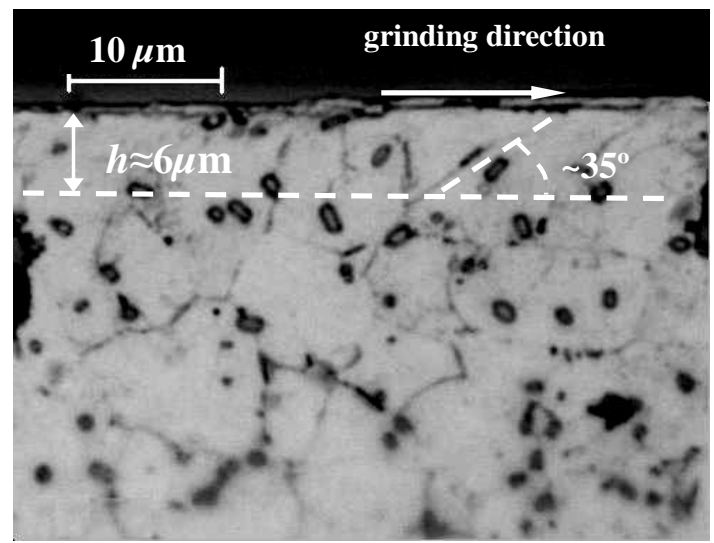

(c) PG3 $\left(a_{p}=0.025 \mathrm{~mm}\right)$

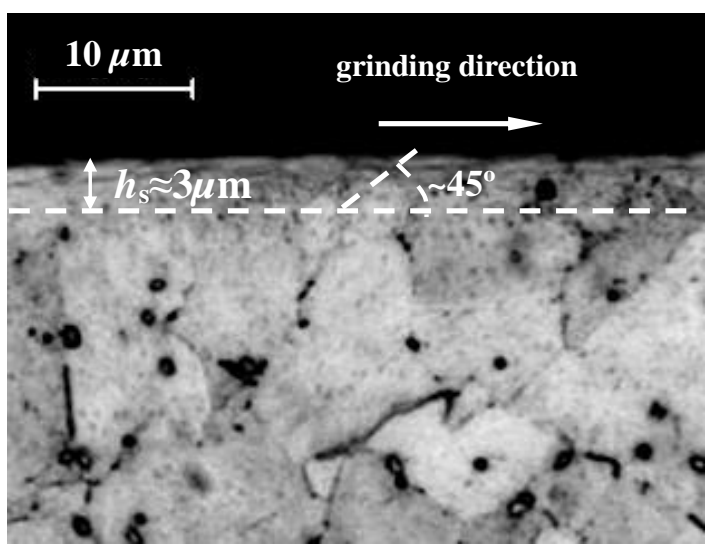

(b) PG1 $\left(a_{p}=0.005 \mathrm{~mm}\right)$

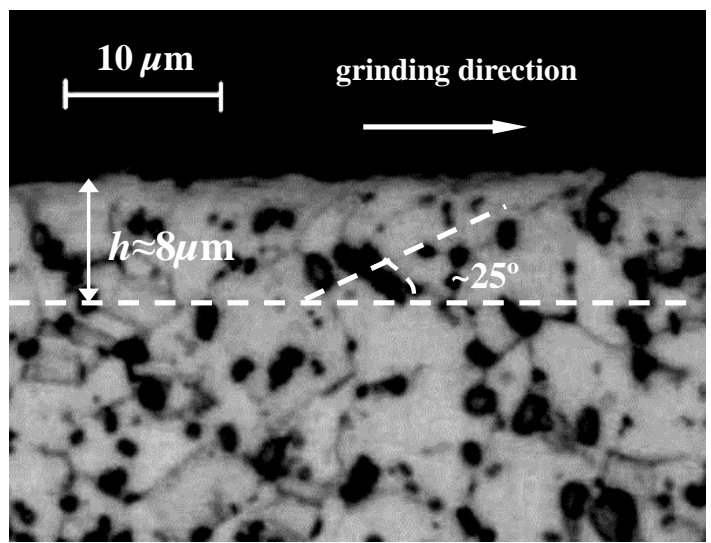

(d) PG5 $\left(a_{p}=0.04 \mathrm{~mm}\right)$

Fig.9 Microstructure metallograph of GH4169 after plain grinding with different $a_{p}$

In Fig.9, the microsections parallel to the grinding direction for the ground GH4169 samples are given. Samples PG1, PG3 and PG5 correspond to grinding parameters with different depths of cut $a_{p}=0.005 \mathrm{~mm}, 0.025 \mathrm{~mm}$ and $0.04 \mathrm{~mm}$. The grinding direction is from left to right. Compared with the metallograph of the unprocessed original state of the bulk material in Fig.9(a), the microstructure of the ground PG1 sample (with $a_{p}=0.005 \mathrm{~mm}$ ) does not have obvious shape or size changes in metallurgy; the degree of deformation of grains within the subsurface layer is also unobvious; the plastic deformation shown by lattice distortion or skewness is not remarkable and the visible and discernable depth that plastice deformation may reach to (thickness of the plastically-deformable layer) is only about $3 \mu \mathrm{m}$. 
In Fig.9(c) and (d), when the depth of cut $a_{p}$ increases to $0.025 \mathrm{~mm}$ and $0.04 \mathrm{~mm}$, the grains in the vicinity of the ground surface are apparently stretched and distorted along with the grinding direction. In view of the larger grinding parameter values of $a_{p}$, the thickness that the plastic deformation can reach to correspondingly increases to about $6 \sim 8 \mu \mathrm{m}$; the skewness angle of grain flow lines reduces from around $45^{\circ}$ to around $25^{\circ}$ which means the degree of grain skew and elongation towards the grinding direction has been enhanced; the grain aspect ratio also consequently increases.

On the other hand, seen from the top view as shown in Fig.10, no visible crack or defect could be found on the ground surfaces of sample PG1 considering its $a_{p}$ and material removal rate are small. Only clear scratches engraved by the abrasive grits are seen along the grinding
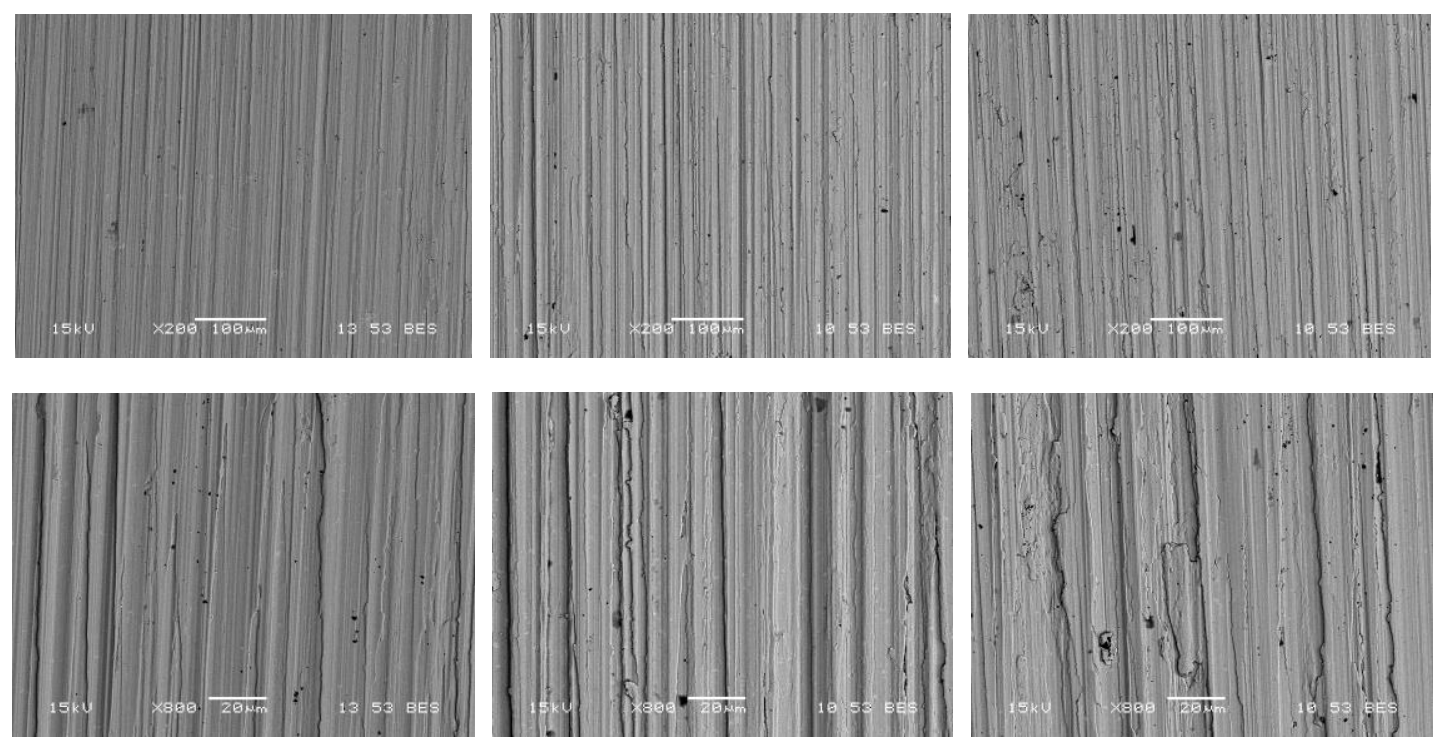

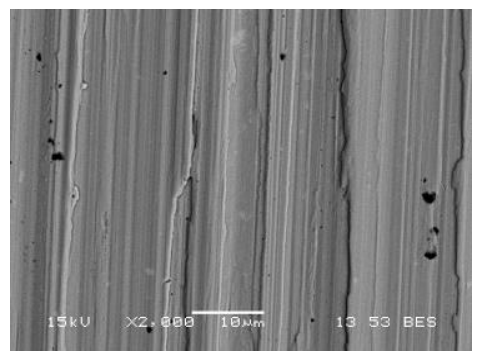

(a) PG1

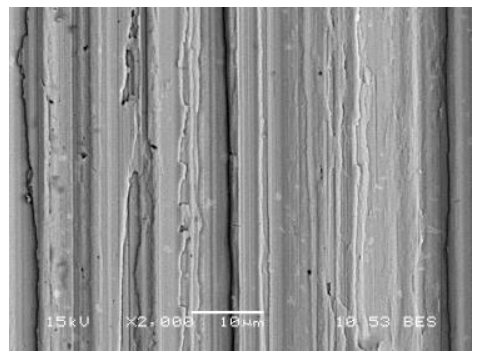

(b) PG3

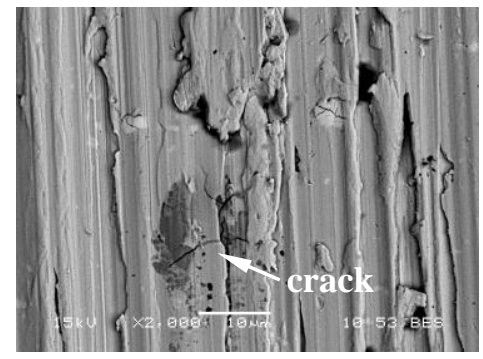

(c) PG5

Fig.10 SEM micrographs of the GH4169 samples by plain grinding with different $\boldsymbol{a}_{p}$ direction even when the maginfication is $2000 \mathrm{X}$. When the $a_{p}$ increases to $0.025 \mathrm{~mm}$, side 
flow and smeared material are observed in the area of the feed marks for sample PG3; however, when $a_{p}$ further increases to $0.04 \mathrm{~mm}$, the surface of sample PG5 has cracks perpendicualr to the grinding direction; some material broken off from the workpiece also overlaps on the machined surfaces. Its surface behavior is apparently deteriorated and worse than that of samples PG1and PG3.

\section{CONCLUSIONS}

Based on the detailed analyses and experiment study of the grinding of GH4169 nickel-base superalloy, some conclusions related to its grindability and surface integrity may be drawn as follows:

(1) For the external grinding, the depth of cut $a_{p}$ and wheel speed $v_{s}$ are the main influencing factors on the surface roughness $R_{a}$. Within the grinding parameters range researched, the surface roughness $R_{a}$ will reduce if the depth of cut $a_{p}$ reduces or the wheel speed $v_{s}$ increases. For the plain grinding, the depth of cut $a_{p}$ shows a more profound and remarkable effect on th surface roughness $R_{a}$. When the depth of cut $a_{p}$ increase from $0.005 \mathrm{~mm}$ to $0.04 \mathrm{~mm}$, the surface roughness values are nearly tripled, rising from $0.284 \mu \mathrm{m}$ to $0.896 \mu \mathrm{m}$. Thus, reasonable choice and control of the wheel speed $v_{s}$ and depth of cut $a_{p}$ will effectively improve the ground surface quality.

(2) External grinding is advantageous in securing compressive residual stress on the machined surface; while plain grinding is prone to producing adverse tensile residual stress on the machined surface. For plain grinding, all residual stresses profiles within the thin subsurface layer exhibit tensile residual stresses with their maximum tensile stress at the surface. Once the excessive tensile residual stress exceeds the material strength of GH4169, adverse 
perpendicular cracks will appear which will largely reduce the performance of machined components.

(3) For the external grinding, the microhardness of machined surfaces are slightly above that of the bulk material $\left(H V_{0} \approx 480\right)$ which means the externally-ground surfaces are in some kind of work-hardened state; while for plain grinding, all the surface's and subsurface's mircohardness measured are below that of the bulk material. With the increase of the depth below surface, the microhardness value will gradually approach that of the bulk material.The thickness of the material-altered layer where microhardness varies will increase with the increase of depth of cut $a_{p}$. When $a_{p}$ increases from $0.005 \mathrm{~mm}$ to $0.04 \mathrm{~mm}$, the thickness of microhardness variation will increase from $200 \mu \mathrm{m}$ to $360 \mu \mathrm{m}$.

(4) For plain grinding, the subsurface microstructure of the material below the surface will be stretched and distorted along the grinding direction. The degree of deformation of grain lattices depends on the depth of cut $a_{p}$, which brings with it different degrees of grinding force and friction force on the interface. The PG5 sample's surface ground by depth of cut $a_{p}=0.04 \mathrm{~mm}$ has the most remarkable change of mirocstructure, with the grain skewness angle around $25^{\circ}$ and the thickness of the plastic deformation layer about $6 \sim 8 \mu \mathrm{m}$. This kind of large depth of cut should be undoubtedly avoided during the practical grinding of GH4169 because it will cause fatal cracks on the machined surface.

\section{ACKNOWLEDGEMENTS}

The research is supported by the National Natural Science Foundation of China (51275423) and 111 Project (B13044). The authors would like to give their thanks to Professor Jingxin 
Ren and Mr Xinchun Huang for their instructive and helpful discussion during experiment, and special thanks to Professor Frank Travis for his assistance on proof reading this article.

\section{REFERENCE}

[1] M. Gu, China Aeronautical Materials Handbook, 2nd ed., China Standard Press, Beijing, 2001.

[2] J. Liu, J. Cao, X. Lin, X. Song, J. Feng, Microstructure and mechanical properties of diffusion bonded single crystal to polycrystalline Ni-based superalloys joint, Materials \& Design, 49 (2013) 622-626.

[3] B. Griffiths, Manufacturing Surface Technology - Surface integrity and functional performance, Penton Press, London, 2001.

[4] Y.B. Guo, W. Li, , I.S. Jawahir, Surface integrity characterization and prediction in machining of hardened and difficult-to-machine alloys: a state-of-art research review and analysis, Machining Science and Technology 13 (2009) 437-470.

[5] E.O. Ezugwu, J. Bonney, Y. Yamane, An overview of the machinability of aeroengine alloys, Journal of Materials Processing Technology, 134 (2003) 233-253.

[6] D. Novovic, R.C. Dewes, D.K. Aspinwall, W. Voice, P. Bowen, The effect of machined topography and integrity on fatigue life, International Journal of Machine Tools and Manufacture, 44 (2004) 125-134.

[7] D. Ulutan, T. Ozel, Machining induced surface integrity in titanium and Nickel alloys: A review, International Journal of Machine Tools and Manufacture, 51 (2011) 250-280.

[8] I.S. Jawahir, E. Brinksmeier, R. M'Saoubi, D.K. Aspinwall, J.C. Outeiro, D. Meyer, D. Umbrello, A.D. Jayal, Surface integrity in material removal processes: Recent advances, CIRP Annals - Manufacturing Technology, 60 (2011) 603-626.

[9] X.P. Xu, Y.Q. Yu, H.J. Xu, Effect of grinding temperatures on the surface integrity of a Nickel-based superalloy, Journal of Materials Processing Technology, 129 (2002) 359-363.

[10] Q. Zhao, Y. Liang, D. Stephenson, J. Corbett, Surface and subsurface integrity in 
diamond grinding of optical glasses on Tetraform 'C', International Journal of Machine Tools and Manufacture, 47 (2007) 2091-2097.

[11] V. Bushlya, J. Zhou, J.E. Ståhl, Effect of Cutting Conditions on Machinability of Superalloy Inconel 718 During High Speed Turning with Coated and Uncoated PCBN Tools, Procedia CIRP, 3 (2012) 370-375.

[12] D. Wenfeng, X. Jiuhua, C. Zhenzhen, S. Honghua, F. Yucan, Grindability and Surface Integrity of Cast Nickel-based Superalloy in Creep Feed Grinding with Brazed CBN Abrasive Wheels, Chinese Journal of Aeronautics, 23 (2010) 501-510.

[13] N. A. Abukhshim, P. Mativenga, M. A. Tsheikh, Heat Generation and Temperature Prediction in Metal Cutting: A Review and Implications for High Speed Machining, International Journal of Machine Tools and Manufacture, 8 (2006) 782-800

[14] S. Malkin, C. Guo, Thermal Analysis of Grinding, CIRP Annals - Manufacturing Technology, 56 (2007) 760-782.

[15] X.D. Lu, J.H. Du, Q. Deng, High temperature structure stability of GH4169 superalloy, Materials Science and Engineering: A, 559 (2013) 623-628.

[16] X. Kong, B. Li, Z. Jin, W. Geng, Broaching Performance of Superalloy GH4169 Based on FEM, Journal of Materials Science \& Technology, 27 (2011) 1178-1184.

[17] C. Xue, W. Chen, Adhering layer formation and its effect on the wear of coated carbide tools during turning of a Nickel-based alloy, Wear, 270 (2011) 895-902.

[18] D.C. Montgomery, Design and Analysis of Experiments, 6th ed., John Wiley \& Sons, New York, 2005.

[19] J.C. Outeiro, J.C. Pina, R. M'Saoubi, F. Pusavec, I.S. Jawahir, Analysis of residual stresses induced by dry turning of difficult-to-machine materials, CIRP Annals Manufacturing Technology, 57 (2008) 77-80.

[20] F. Gunnberg, M. Escursell, M. Jacobson, The influence of cutting parameters on residual stresses and surface topography during hard turning of $18 \mathrm{MnCr} 5$ case carburised steel, Journal of Materials Processing Technology,174 (2006) 82-90.

[21] X. Chen, W. Brian Rowe, Analysis and simulation of the grinding process. Part II: Mechanics of grinding, International Journal of Machine Tools and Manufacture, 36 (1996) 883-896. 
